\title{
Logística dos macroprocessos em uma processadora de minério de ferro atuante no estado do Pará
}

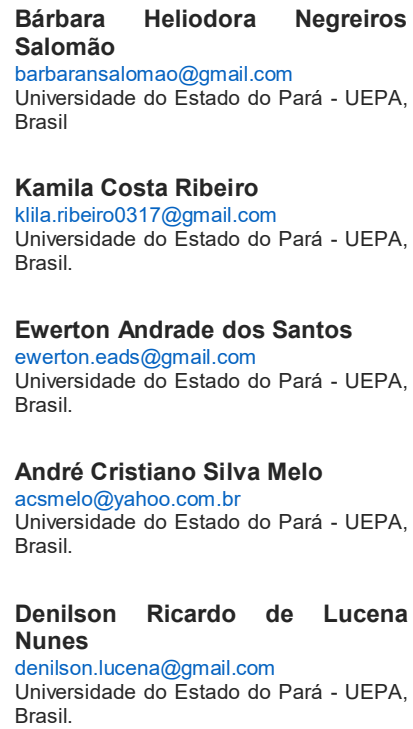

André Cristiano Silva Melo acsmelo@yahoo.com.br Universidade do Estado do Pará - UEPA, Brasil.

Denilson Ricardo de Lucena Nunes

denilson.lucena@gmail.com Universidade do Estado do Pará - UEPA Brasil.

\author{
RESUMO
}

Dado o atual cenário mundial e a necessidade de aumento de competitividade em todos os setores econômicos, o estudo logístico vem, progressivamente, ampliando sua importância dentro das organizações, uma vez que passou a ser reconhecido como uma das principais áreas de conhecimento geradora de diferenciais competitivos. Assim, esta pesquisa caracterizou a logística dos macroprocessos de Extração e Beneficiamento, em uma mineradora de ferro atuante no Estado do Pará, visando potencializar o suporte a decisões estratégicas que tornem os processos operacionais mais eficientes. Desse modo, este trabalho configurou-se como um estudo de caso, onde foram identificados, mapeados e caracterizados os componentes e recursos logísticos envolvidos nos macroprocessos supracitados. Para alcançar o objetivo proposto, foi realizada uma revisão bibliográfica e documental, referentes aos processos analisados, que possibilitou maior detalhamento sobre a logística associada à cadeia produtiva do minério de ferro desenvolvida no Estado do Pará, bem como sobre os recursos logísticos envolvidos. Dessa maneira, foi apresentado um quadro resumo e um mapa de processos que, respectivamente, identifica os recursos e mostra como estes ocorrem nos macroprocessos estudados, além de evidenciar quais as consequências do emprego destes recursos na cadeia produtiva analisada.
\end{abstract}

PALAVRAS-CHAVE: Cadeia produtiva do minério de ferro; Mapeamento de processos; Componentes logísticos operacionais. 


\section{INTRODUÇÃO}

Para Carvalho et al. (2014, p. 204), em termos de demanda, o mercado de minério de ferro é altamente dependente da produção de aço, que representa mais de $90 \%$ desta demanda. Analisando-se a oferta, o minério de ferro é dependente quase exclusivamente da localização das minas de exploração, sendo as maiores localizadas na Austrália, Brasil, Rússia, Índia e China. Assim, quanto mais próximas as minas estiverem do consumo para determinado tamanho do minério, maior será a representatividade de mercado dos países produtores, por esse motivo, países como Austrália e Brasil, possuem cerca de $60 \%$ de representatividade de mercado da produção do granulado de minério de ferro (CARVALHO et al., 2014).

De acordo com Faria et al. (2016), em resposta a evolução da demanda, o setor de mineração iniciou um ciclo de reorganização de processos e operações, e diversas empresas brasileiras aceleraram a produção de suas reservas. Conforme a USGS (2013), o Brasil é o segundo maior país com reserva de minério de ferro do mundo. Segundo IBRAM (2015), em 2014, o Brasil atingiu 400 milhões de toneladas de ferro produzidas, onde, para DNPM (2016), os principais estados produtores foram: Minas Gerais $(68,4 \%)$, Pará $(29,2 \%)$ e Mato Grosso do Sul $(1,2 \%)$, concentrando $98,8 \%$ da produção brasileira deste minério.

Segundo a IBRAM (2015), a balança mineral do Pará apresentou em 2013 um saldo total de US\$ 11.824 bilhões, havendo em 2014 uma redução no saldo que resultou num total de US\$ 9.294 bilhões. As exportações de bens minerais representaram 70,6\% de todas as exportações do estado em 2014. Assim, 29\% d o minério de ferro exportado pelo Brasil em 2014 saiu do Pará. A partir de tais números, torna-se importante o estudo logístico da cadeia produtiva do minério de ferro no Pará sob vários aspectos, no social pelas potenciais oportunidades de geração de empregos e no científico, para identificar e preencher possíveis lacunas na literatura relacionadas ao tema, já que este setor, como outros setores produtores de commodities, é intensivo em atividades logísticas, apresentando assim vantagens competitivas fortemente influenciadas pelo desempenho destas atividades. Desta forma, novos conhecimentos sobre o assunto podem levar à melhor compreensão sobre os processos envolvidos, potencializando a proposição de novas estratégias voltadas à maior efetividade logística nessa cadeia produtiva.

Dada a relevância social, acadêmica e econômica, esta pesquisa dispôs-se a responder a seguinte questão: Quais as características atuais das operações logísticas que suportam os macroprocessos de extração e beneficiamento em uma mineradora de ferro atuante no Pará?

Esta pesquisa buscou compilar informações sobre os processos de Extração e de Beneficiamento, considerando a cadeia do minério de ferro, em uma empresa atuante no Estado do Pará, com o objetivo de caracterizar a logística, sob a perspectiva dos componentes logísticos operacionais envolvidos. Para tal, foram identificadas as operações executadas na cadeia estudada, através do mapeamento de processos, observando-se a alocação e uso dos recursos envolvidos. 


\section{REFERENCIAL TEÓRICO}

Nesta seção serão apresentadas definições e características sobre as pesquisas desenvolvidas sobre os temas que fundamentam o desenvolvimento dessa pesquisa, a saber: Cadeia produtiva do minério de ferro; Mapeamento de processos; Componentes logísticos operacionais.

\section{CADEIA PRODUTIVA DO MINÉRIO DE FERRO}

A ideia de cadeia produtiva, ou o mesmo que supply chain, numa definição simplificada, pode ser compreendida como um conjunto de elementos ou sistemas que interagem em um processo produtivo para oferta de produtos ou serviços ao mercado consumidor (GONÇALVES; LEITE; SILVA, 2012).

Lovón-Canchumani, Lima e Oliveira (2015), em um estudo sobre avaliação do clico de vida do minério de ferro em mineradora de Minas Gerais, decompôs a cadeia produtiva deste minério nas seguintes etapas: a) Lavra; b) beneficiamento; c) Transporte; e d) Pelotização. A Lavra é um subsistema composto por atividades de desmonte, carregamento em caminhões e transporte por sistema de correias fixas e móveis. O Beneficiamento é o subsistema responsável pela transformação física do minério, sendo composto pelas atividades de britagem, peneiramento, moagem, flotação e espessamento. Ao transporte, além de correias, a empresa usava minerodutos, a partir dos quais a polpa de minério de ferro, beneficiado em solução aquosa, era bombeada através de dois minerodutos, responsáveis por movimentar o minério entre as unidades da empresa. No subsistema, pelotização, o minério de ferro sai de uma unidade localizada em Minas Gerais e chega ao porto, no Espirito Santo, onde passa pelo processo de preparação, pelotização e endurecimento, para produção de pelotas (LOVÓN-CANCHUMANI, LIMA e OLIVEIRA, 2015).

De acordo com Vale (2016), nas etapas de produção do minério de ferro, realizam-se os seguintes processos: extração de minério ou estéril, designação de veículos a britadores ou depósitos, transporte de minério ou estéril, britagem primária de minério, designação de veículos a minas, transporte de minério britado via correias transportadoras, britagem secundária e peneiramento de minério britado, transporte por correias transportadoras de minério beneficiado (granulado, sinter feed e pelet feed), armazenagem e estocagem de minério beneficiado em pátios, recuperação e transporte de minério beneficiado, armazenagem e estocagem de minério beneficiado em silos, descarregamento de minério beneficiado em vagões, transporte ferroviário de minério beneficiado, descarregamento e transporte de minério beneficiado, armazenagem e estocagem de minério beneficiado em pátios portuários, recuperação e embarque de minério beneficiado em navios. Tais processos são ilustrados na Figura 1.

No entanto, considerando uma definição mais ampla, nesta pesquisa, a cadeia produtiva do minério de ferro foi dividida em 4 macroprocessos, a saber:

a) Extração: ocorre em minas subterrâneas ou a céu aberto, destacando-se os processos de Lavra (minério e estéril), Carregamento para transporte, Designação e Transporte até os pontos de processamento (minério) ou armazenagem (estéril), Descarregamento para Britagem primária (minério) ou para Armazenagem (estéril) e Designação a pontos para novos carregamentos;

b) Beneficiamento: Considera atividades de Transporte do minério já britado primariamente até as atividades Britagem e Peneiramento, que resultam na produção de 
granulado, sinter feed e pelet feed, Movimentação destes até áreas exclusivas de armazenagem (pátios), Manutenção e Armazenagem dos estoques, e Recuperação e Movimentação até os Silos de carregamento; e Carregamento destes produtos nos veículos, para o transporte;

c) Transporte: Corresponde ao transporte de longo curso de granulado, sinter feed e pelet feed até os pontos onde estes serão despachados para seus clientes. No caso em estudo, da Serra dos Carajás (PA) ao Terminal Marítimo de Ponta da Madeira (MA);

d) Expedição: inicia com o Descarregamento e Movimentação de granulado, sinter feed e pelet feed) até as áreas de estocagem, seguida pela Manutenção e Armazenagem dos estoques, Recuperação e Embarque destes materiais nos veículos para o transporte aos seus destinos.

Figura 1 - Processos da cadeia produtiva do minério de ferro

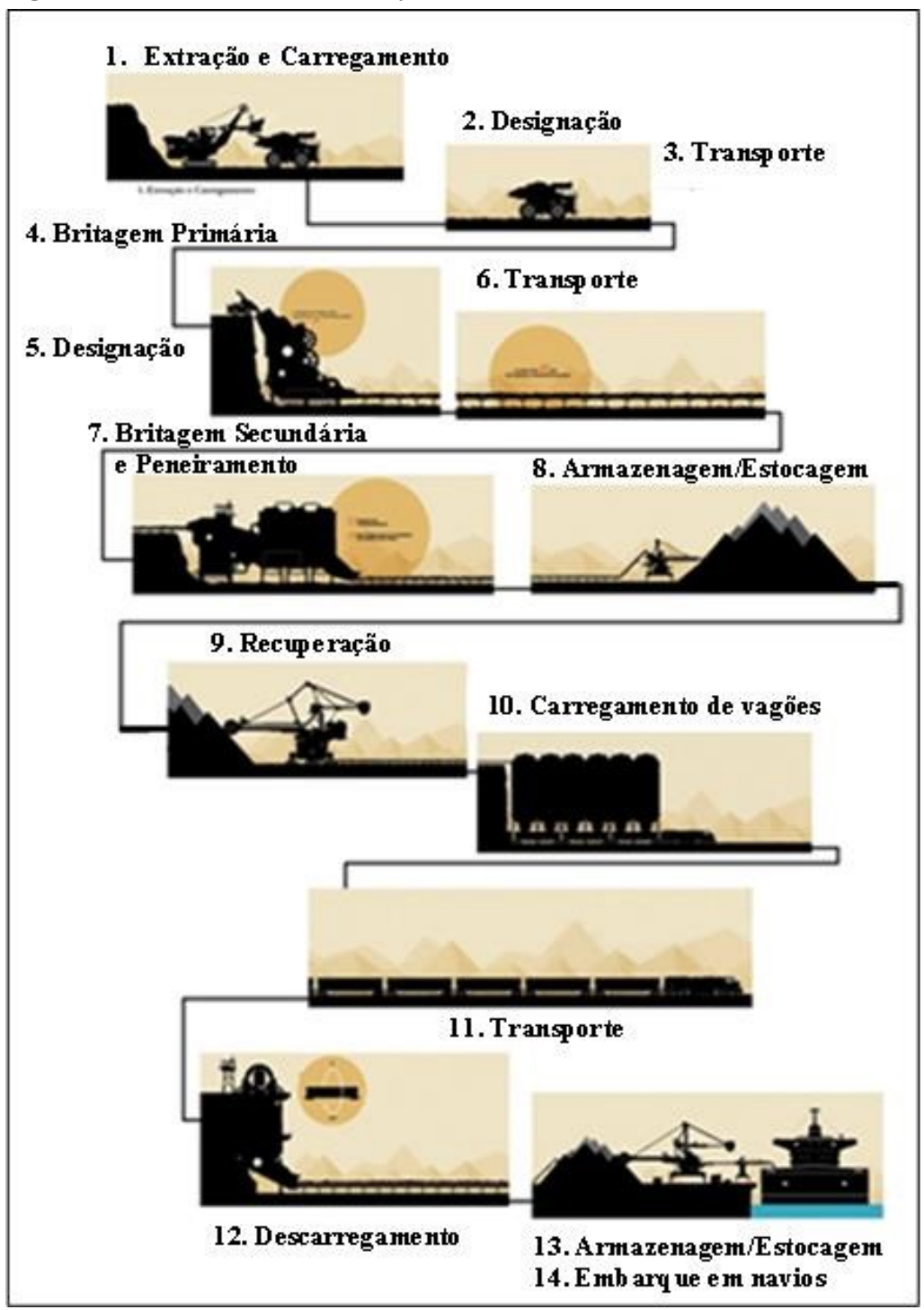

Fonte: Autores (2018) 


\section{COMPONENTES LOGÍSTICOS OPERACIONAIS}

Em consequência da competição global e do aumento da fragmentação dos processos nas organizações, a necessidade de maior integração entre as diferentes unidades empresariais e destas com fornecedores e consumidores vem crescendo rapidamente, tendo grande relevância competitiva (VERHETSEL et al. 2014).

Para Tan (2002), Christopher (2016) e Carneiro et al. (2007), a partir desse cenário tornase essencial o estudo logístico e de Gerenciamento da Cadeia de Suprimentos (Supply Chain Management - SCM), visando ampliar vantagem competitiva, por meio de estratégias e práticas capazes de reduzir incertezas sobre as demandas, satisfazendo, assim, às necessidades dos seus clientes.

De acordo com Fleury et al. (2012), o crescimento empresarial é resultante de várias decisões estratégicas que transcendem os aspectos mercadológicos e operacionais. Assim, os componentes logísticos, tornam-se essenciais ao sucesso operacional de uma cadeia (SIMCHI-LEVI, 2010), devendo sua análise ser feita a partir destes componentes envolvidos nos seus processos (CHOPRA e MEINDL, 2016; BOWERSOX et al., 2014). Nesse sentido, a integração que relacionar os fluxos de negócios para atender aos requisitos dos clientes, pode ser considerada uma vantagem competitiva, já que visa agregar valor às partes interessadas (MELO; ALCÂNTARA, 2011 apud SANTOS; MARINS, 2015). Assim, o desempenho logístico envolve 4 fatores-chave: estoques, transportes, instalações e informações (CHOPRA; MEINDL, 2016). Tais fatores são mais bem definidos e caracterizados a seguir.

- Estoques - são importantes na rede de suprimento devido à incertezas entre oferta e demanda, constituindo amortecedores desse descompasso na cadeia e agregando valor de tempo a bens ou serviços fornecidos, sendo considerado parte vital da logística, já que qualquer mudança de gestão pode alterar o desempenho (custos e nível de serviço) empresarial (BALLOU, 2006; CHOPRA e MEINDL, 2003; CORRÊA, 2010). Segundo Gonçalves et al. (2012), este componente pode ser considerado a unidade de recursos materiais entre etapas de um processo que interagem dentro do canal logístico;

- Transportes - refere-se à atividade logística que geograficamente movimenta e posiciona os estoques, tendo suas principais funções associadas às dimensões de tempo e utilidade de lugar (BOWERSOX et al., 2007; FLEURY; WANKE; FIGUEIREDO, 2000). Chopra e Meindl (2003) definem o transporte como um elemento fundamental e integrador de toda cadeia de suprimentos, onde os bons resultados de desempenho estão estreitamente associados à sua boa utilização;

- Instalações - diz respeito ao local onde bens são armazenados, montados ou fabricados (CHOPRA; MEINDL, 2016). Segundo Ballou (2001), precisam ser localizadas e ter tamanhos adequados às demandas, a fim de buscar redução dos custos logísticos. Métodos e sistemas devidamente adequados para armazenar, possibilitam reduções de custos, melhorias de qualidade e agregação valor de tempo e lugar, influenciando a capacidade de armazenagem e custo de serviço ao cliente (DIAS, 2012; LEITE et al., 2016);

- Informações - podem influenciar diretamente o desempenho logístico, já que informações de melhor qualidade permitem tomar decisões que tornam a cadeia mais eficiente e eficaz (CHOPRA; MEINDL, 2016). Este componente pode ser considerado o principal agente facilitador de integração na cadeia de suprimento, sendo imprescindível para minimizar necessidades de ativos totais, de níveis de estoques e de trade-offs, promovendo ainda aumento da flexibilidade logística sobre o uso dos recursos e, 
consequentemente, melhores níveis de serviços (SIMCHI-LEVI, 2010; BOWERSOX et al., 2014).

\section{MAPEAMENTO DE PROCESSOS}

Todas as operações que contribuem para prestação de serviços ou produção de produtos são alimentadas por vários processos que permitem a transformação dos recursos de entrada (inputs) em elementos de saída (outputs) (SLACK; CHAMBER; JOHNSTON, 2009). Segundo Nagel e Roseman (1999) e Hammer; Champy (1994), um processo pode ser visto como um conjunto de procedimentos e recursos, guiados por uma ordenação lógica (em paralelo e/ou em série) norteada para agregação de valor para o consumidor.

Desta forma, o Mapeamento de Processos (MP) surge como uma importante técnica de gestão de processos, permitindo conhecer com detalhes as operações que ocorrem durante a realização das tarefas (MILAN; VERSETTI, 2012). O MP assegura ao sistema produtivo maior fluidez dos fluxos, mantendo os limites de decisão, evitando erros que possam acarretar em ineficiência e ineficácia do processo (ARAUJO; GARCIA; MARTINES, 2011). Contudo, para melhor entendimento da organização e produção é necessário entender o grau de hierarquia dos processos na cadeia produtiva, a saber: Macroprocesso, Processo, Subprocesso e Atividades, como no Quadro 1 (CANDIDO; SILVA; ZUHLKE, 2008).

Quadro 1- Grau de hierarquia dos processos

\begin{tabular}{|l|l|}
\hline Grau de hierarquia & Conceito \\
\hline Macroprocesso & $\begin{array}{l}\text { É a identidade da gerência no organograma geral, ou seja, é o } \\
\text { nome pelo qual a unidade pode ser conhecida. }\end{array}$ \\
\hline Processo & $\begin{array}{l}\text { Pode ser dividido em processos de realização (natureza da } \\
\text { função da gerência, ou seja, a razão pela qual os clientes a } \\
\text { acionam); de apoio (garantem suporte direto à concretização do } \\
\text { produto fim); e de gestão (não estão diretamente associadas ao } \\
\text { processo de produção, sendo responsáveis por diretrizes } \\
\text { referentes à gestão de pessoas e unidade, de acordo com as } \\
\text { normas coorporativas). }\end{array}$ \\
\hline Subprocesso & $\begin{array}{l}\text { Conjunto de atividades referentes a similares dentro de um } \\
\text { processo. }\end{array}$ \\
\hline Atividades & Cadeias operacionais representadas em forma de fluxogramas. \\
\hline
\end{tabular}

Fonte: Baseado em Candido, Silva e Zuhlke (2008)

Neste estudo, a ferramenta usada ao mapeamento dos macroprocessos analisados foi o Fluxograma que é uma das representações gráficas mais utilizadas para estruturar as rotinas existentes em qualquer setor de trabalho (FONTES; FONTES, 2008), permitindo esquematizar e visualizar linearmente todos os processos de forma racional, clara e sucinta, facilitando o entendimento geral e decisões de melhorias no sistema produtivo (GODOY et al., 2013).

Segundo Gonçalves e Almeida Junior (2012), o fluxograma faz uso de símbolos que indicam operações, movimentação, inspeção, espera, ponto de decisão e depósito, como mostrado na Figura 2, que são conectados por setas representando o sentido do fluxo do processo produtivo. 
Figura 2 - Principais símbolos utilizados no fluxograma

\begin{tabular}{|l|l|l|l|l|l|l|}
\hline Operações & Movimentação & Inspeção & Espera & Depósito & $\begin{array}{c}\text { Sentido } \\
\text { do fluxo }\end{array}$ & $\begin{array}{c}\text { Ponto de } \\
\text { Decisão }\end{array}$ \\
\hline$\square$ & $\longrightarrow$ & 0 & $\square$ & & $\longrightarrow$ & \\
\hline
\end{tabular}

Fonte: Adaptado D’Ascenção (2001)

É válido ressaltar que, no fluxograma desenvolvido neste trabalho, para representar operações de movimentações, foi feita a troca do símbolo de Movimentação pelo símbolo similar ao de Operação. Contudo, tal fato não comprometeu o resultado do estudo.

\section{PROCEDIMENTOS METODOLÓGICOS}

Para alcançar o objetivo proposto, realizou-se uma revisão bibliográfica e documental na qual caracterizou-se a logística dos macroprocessos de Extração e Beneficiamento da cadeia do minério de ferro em uma empresa atuante no Estado do Pará, bem como de todos os processos envolvidos nestas etapas.

Após o levantamento bibliográfico e documental, realizado por meio de pesquisa e leitura de artigos (congressos e periódicos) e documentos disponibilizados (planilhas e relatórios de produção etc.), além de entrevistas não estruturadas com funcionários da empresa objeto de estudo, foram identificados os processos envolvidos nos macroprocessos de extração e beneficiamento, a partir de uma análise detalhada dos processos atualmente desenvolvidos, desde a lavra (minério e estéril) até o carregamento dos equipamentos de transporte com o minério já processado (granulado, sinter feed e pelet feed). De posse de tais informações, por meio do fluxograma vertical, foi proposto o mapa dos processos e a identificação dos recursos logísticos considerados em cada atividade. Na quarta etapa foi caracterizado como os recursos logísticos, por meio da alocação destes aos componentes logísticos envolvidos, auxiliam os processos analisados e como contribuem para agregação de valor aos produtos gerados. Posteriormente, por meio da caracterização dos componentes logísticos operacionais envolvidos em cada processo identificado, foi realizada a caracterização logística dos macroprocessos considerados, onde foi elaborado um quadro resumo, que visou facilitar a visualização das atribuições de cada componente logístico nestes macroprocessos. Dessa forma, as etapas do estudo ocorreram conforme a Figura 3.

Figura 3 - Etapas da pesauisa

\begin{tabular}{|c|c|c|c|c|}
\hline $\begin{array}{l}\text { Levantar } \\
\text { bibliografia } \\
\text { e documen- } \\
\text { tos }\end{array}$ & $\begin{array}{c}\text { Identificar } \\
\text { os } \\
\text { processos } \\
\text { envolvidos } \\
\text { dentro dos } \\
\text { macro- } \\
\text { processos }\end{array}$ & $\begin{array}{l}\text { Mapear os } \\
\text { processos e } \\
\text { Identificar } \\
\text { recursos } \\
\text { logísticos } \\
\text { das } \\
\text { atividades }\end{array}$ & $\begin{array}{l}\text { Caracterizar } \\
\text { como os } \\
\text { recursos } \\
\text { logísticos } \\
\text { auxiliam os } \\
\text { processos }\end{array}$ & $\begin{array}{c}\text { Caracterizar } \\
\text { a logística } \\
\text { dos macro- } \\
\text { processos }\end{array}$ \\
\hline
\end{tabular}

Fonte: Autores (2018)

\section{RESULTADOS E DISCUSSÕES}

A empresa estudada, no Sudeste Paraense, atua no complexo de Carajás, no município de Parauapebas (CABRAL, 2016), sendo essa unidade responsável pela expedição de minério 
com teor de ferro, em média 66,7\% (BÔAS, 2016). O volume produzido em 2016, nesta unidade, foi de 148,1 milhões de toneladas, entre as variedades granulado, sinter feed e pelet feed, indicando um aumento de 18,6\%, comparado com 2015 (VALE, 2017). Esta unidade opera desde de 1985 e, atualmente, é composta por 5 minas a céu aberto. Para a comercialização de minério de ferro, diversas etapas são executadas, contudo, na presente pesquisa foram analisados apenas os macroprocessos de Extração e de Beneficiamento.

\section{ANÁLISE LOGÍSTICA DO MACROPROCESSO DE EXTRAÇÃO}

Na Extração o componente Estoques deve manter o fluxo contínuo de produção em todas as etapas, bem como, evitar filas de caminhões fora de estrada (CFE) tanto descarregados, durante o carregamento (minério e estéril), nas frentes de lavra, quanto carregados, durante o descarregamento (minério) para a britagem primária (britadores móveis e semimóveis). Posterior à lavra do material, parte deste (minério) é coletada e direcionada para beneficiamento e posterior comercialização, e outra parte (estéril) é direcionada para armazenagem em pilhas específicas (Depósitos de estéril), em um dos 5 depósitos existentes, onde é descarregado e mantido em condições seguras para uso futuro (COELHO et al., 2016).

Já o minério de ferro é destinado (via CFE) aos britadores alocados às minas das quais foi originado (extraído). Contudo, caso haja fila de CFE na chegada destes aos britadores, o minério é descarregado em "pulmões", como é denominada a região próxima aos britadores, evitando o congestionamento no local.

Vale destacar que os estoques em trânsito, tanto de estéril quanto de minério, também estão presentes durante a execução deste macroprocesso, respectivamente na movimentação dos CFE aos pontos de armazenagem ou aos britadores. Ademais, os estoques entre os processos de Extração podem ser caracterizados como de baixa variedade e alto volume, pois neste processo apenas dois tipos de materiais (minério e estéril) são movimentados e o elevado rendimento nas minas contribui à formação de muitos estoques de minério de ferro.

No que se refere ao componente Transportes, o modal rodoviário é de suma importância para as atividades deste macroprocesso, já que promove a conexão entre as etapas desenvolvidas. Segundo Coelho et al. (2016), 430 veículos são usados na execução da lavra, entre eles, escavadeiras, perfuratrizes, motoniveladoras, carregadeiras e CFE.

Ao desenvolvimento dos processos, aproximadamente, 121 CFE de 240 ou 400 toneladas são carregados na atividade de lavra e conduzidos aos britadores, no início do macroprocesso de Beneficiamento ou aos depósitos específicos, os quais são organizados de acordo com o tipo de material que está sendo transportado, sendo estes, respectivamente, minério e estéril (BRANCO, 2013).

O número de viagens deste traslado é realizado com alta frequência, para manter o ritmo acelerado da produção. Além disso, uma elevada quantidade de caminhões é usada para um maior dinamismo da cadeia de produção.

Já as Instalações que apoiam o macroprocesso de Extração, encontram-se nos extremos da operação, a frente de lavra (Instalação 1), no início do macroprocesso, e a britagem primária (Instalação 2), na sua finalização. Na frente de lavra ocorre a retirada de minério e estéril a céu aberto, além de realizadas operações de preparo da mina e retirada do minério (e estéril), as quais designam elevada utilização de equipamentos, como 
perfuratrizes, motoniveladoras, CFE, escavadeiras e pás-carregadeiras (Vale, 2016). Ademais, esta estrutura conta com auxílio de outros equipamentos na limpeza, na abertura de cava ou na drenagem das minas, contribuindo para manutenção das condições operacionais ideais no local.

A britagem primária é realizada por britadores móveis e semimóveis, onde os blocos de minério são reduzidos a partículas com menos de 20 milímetros (Vale, 2016). O minério lavrado passa por processo inicial de britagem, para facilitar o fluxo por longas distâncias, a partir de correias transportadoras, até os demais processos de Beneficiamento. Assim, compreende-se este como um processo de Beneficiamento, mas instalado na "fronteira" entre a Extração e o Beneficiamento.

Sobre o componente Informações, a empresa objeto de estudo utiliza tecnologia avançada para comunicação e monitoramento das operações, com um sistema que permite controlar cada etapa, em tempo real, por meio de satélites (VALE, 2016). Tal investimento justifica-se pela necessidade de trocas de informação mais eficientes e melhor integração das atividades deste macroprocesso, além de proporcionar maior dinamismo entre as atividades. Nesse sentido, este componente tem como objetivo minimizar a formação de filas de CFE entre as etapas de execução deste macroprocesso.

A lavra pode ocorrer simultaneamente em 5 minas distintas, onde dependendo do rendimento podem ser alocados mais recursos (mão de obra, equipamentos, CFE etc.) ao transporte dos materiais extraídos (BRANCO, 2013). Assim, este componente permeia toda organização e planejamento da produção, definindo e mensurando as quantidades necessárias de recursos a cada atividade.

A informação auxilia a definição de rotas dos CFE, sendo tal decisão baseada no tempo de movimentação até a etapa seguinte e na situação desta etapa (nível de ociosidade) no momento estimado para a chegada dos veículos. Ressalta-se que essas decisões ocorrem tanto para veículos com minério, encaminhados para a britagem, quanto para os carregados com estéril, roteados para o armazenamento nos depósitos específicos, considerando-se a menor probabilidade de formação de filas para descarregamento nos processos de destino.

Finalmente, a informação é fundamental ao processo de designação dos veículos, quando, para estes, são definidos, logo após o carregamento (minério ou estéril), os britadores (minério) e depósitos (estéril) e, logo após o descarregamento (minério ou estéril), as novas frentes de lavra que eles se encaminharão, considerando tempos de deslocamento e níveis de ociosidade das instalações de destino no momento estimado para chegada desses veículos, mais uma vez, para evitar filas, quer durante o carregamento quer durante o descarregamento.

\section{ANÁLISE LOGÍSTICA DO MACROPROCESSO DE BENEFICIAMENTO}

Durante o Beneficiamento, os Estoques (granulado, sinter feed e o pelet feed) são armazenados nos 5 pátios da empresa (VALE, 2016). Neste macroprocesso os estoques são caracterizados com altos volumes e baixa variedade, já que, mesmo após as etapas de britagem e peneiramento, apenas três tipos de produtos são armazenados. As correias transportadoras também desempenham um papel importante neste componente logístico, pois, ao movimentar grandes volumes de uma instalação para a outra, tais equipamentos formam estoques em trânsito. A formação de estoques nesta etapa surge da necessidade de manter os fluxos elevados (em escala) e constantes de materiais produzidos nas linhas de produção. 
O componente Transportes é o elemento fundamental para conectar todas as atividades compreendidas no Beneficiamento. Para tal são usadas correias transportadoras para movimentar o minério de ferro, entre a britagem primária e os processos de britagem e peneiramento. Destas etapas resultam granulado, sinter feed e pelet feed, estes produtos que seguem, também por correias transportadoras, para armazenagem nos 5 pátios de estoque, os quais são organizados de acordo com as especificações de cada produto, com auxílio das empilhadeiras (VALE, 2016).

Para o despacho dos produtos e carregamento nos vagões, as pilhas de minérios são movimentadas por recuperadoras que as repõem em correias transportadoras (FARIA, RIBEIRO, VIANA, 2016) que transportam as quantidades pré-definidas até os silos que, assim são carregados, para serem descarregados nos vagões do trem da empresa, com destino ao porto de São Luís (BRANCO, 2013).

Avaliando-se as alternativas de transporte neste macroprocesso, concluiu-se que a empresa opta por tentar manter um fluxo contínuo e em grande escala para as movimentações executadas, afim de manter um ritmo acentuado e um fluxo constante nas correias transportadores. As correias transportadoras permitem um fluxo mais contínuo e constante, com ganhos de escala na movimentação.

As Instalações na etapa de Beneficiamento podem ser divididas em 3 grupos: Beneficiamento e peneiramento, Pátios de Estocagem/Armazenagem e Silos. O conjunto compreendido pela instalação de Beneficiamento e peneiramento engloba os maquinários que realizam os processos de britagem secundária, peneiramento e classificação, responsáveis por agregar mais valor ao minério extraído, a partir da redução da granulometria do minério de ferro, produzindo, para cada tamanho específico de grão de minério, o granulado, o sinter feed e o pelet feed.

Nos Pátios de Estocagem/Armazenagem, ocorrem, além da estocagem/ armazenagem de minérios, recuperação e movimentação dos estoques, por recuperadoras-empilhadeiras, até as correias transportadoras que os conduzirão o aos silos. Nestes os minérios são despejados e armazenados em pilhas de até 18 metros de altura e 50 metros de largura (VALE, 2016), organizadas de acordo com especificações de cada produto (BRANCO, 2013).

Os Silos são usados para carregar os vagões de trem, com os minérios produzidos nas etapas anteriores (FARIA, RIBEIRO, VIANA, 2016) que, posteriormente, serão despachados com destino ao porto de São Luís. Segundo Branco (2013), nos Pátios de estocagem/ armazenagem e nos Silos, também é realizado o blend, que constitui a mistura de minérios com diferentes teores de ferro de modo que os produtos finais atinjam os níveis de concentração de ferro aceitos pelo mercado.

Como supracitado, no que se refere ao componente Informações, o monitoramento das atividades ocorre 24 horas por dia, já que a produção não para e necessita de controle constante das operações (BRANCO, 2013), possibilitando melhor integração entre os elos da cadeia, sobretudo, por evitar que as informações sejam transmitidas de forma distorcida nas várias etapas de produção. No Beneficiamento o controle é executado por um sistema de automação via satélite que monitoram os diferentes elos envolvidos. Tal monitoramento fornece o status das atividades tanto deste macroprocesso como de etapas posteriores ou anteriores, de modo que seja possível tomar decisões voltadas à melhor sincronização dessas atividades.

Via tecnologia de informação (TI) utilizada é possível acompanhar o transporte do minério durante os $85 \mathrm{~km}$ de correias transportadoras, além do processo de 
peneiramento e separação do minério nos três diferentes tamanhos. Após o descarregamento dos silos e o carregamento dos vagões, uma nova informação é transmitida ao macroprocesso anterior para reposição de estoques que foram despachados para o porto. Dessa maneira, toda TI aplicada neste macroprocesso, possibilita um melhor planejamento de produção dos produtos fornecidos pela empresa, bem com auxilia o controle dos estoques e dá suporte às decisões tomadas pela organização.

No Quadro 2 observa-se que o componente informação, tanto na Extração quanto no Beneficiamento, é baseado no uso intenso de TI, favorecendo visualização mais global, em tempo real e de modo integrado da cadeia produtiva, facilitando os fluxos logísticos de modo claro e eficiente. Além disso, a informação auxilia o planejamento e a melhor utilização dos recursos associados aos demais componentes logísticos operacionais (transporte, estoque e instalação) envolvidos nos macroprocessos analisados.

Quadro 2 - Caracterização logística da produção do minério de ferro no Pará

\begin{tabular}{|c|c|c|}
\hline \multirow{2}{*}{ Componentes Logísticos } & \multicolumn{2}{|c|}{ Macroprocessos } \\
\hline & Extração & Beneficiamento \\
\hline Transportes & $\begin{array}{l}121 \text { CFE de } 240 \text { ou } 400 \\
\text { toneladas }\end{array}$ & $\begin{array}{c}85 \mathrm{Km} \text { de correias } \\
\text { transportadoras; e } \\
\text { recuperadoras/recuperadoras- } \\
\text { empilhadeiras } \\
\end{array}$ \\
\hline Informação & $\begin{array}{l}\text { Monitoramento por } \\
\text { satélites; Orientação das } \\
\text { rotas dos caminhões; } \\
\text { Controle do estoque nos } \\
\text { "pulmões". }\end{array}$ & $\begin{array}{l}\text { Monitoramento por satélites; } \\
\text { Status das correias } \\
\text { transportadoras; Controle dos } \\
\text { estoques nos pátios e silos. }\end{array}$ \\
\hline Estoque & $\begin{array}{c}\text { Baixa variedade (minério } \\
\text { de ferro e estéril) e Alto } \\
\text { volume; CFE (em } \\
\text { trânsito); “Pulmões” } \\
\text { (frente de lavra e } \\
\text { britadores); Depósitos } \\
\text { específicos (estéril). }\end{array}$ & $\begin{array}{c}\text { Baixa variedade (minério de } \\
\text { ferro, granulado, sinter feed e } \\
\text { pelet feed) e alto volume; } \\
\text { Correias transportadoras (em } \\
\text { trânsito); Pátios de } \\
\text { estocagem/ armazenagem; e } \\
\text { Silos. }\end{array}$ \\
\hline Instalação & $\begin{array}{c}\text { Frente de Lavra; } \\
\text { Britadores móveis e } \\
\text { semimóveis (britagem } \\
\text { primária). }\end{array}$ & $\begin{array}{l}\text { Beneficiamento (Britadores e } \\
\text { Peineradores) Pátios } \\
\text { (Estocagem/ armazenagem e } \\
\text { Recuperadores); e Silos. }\end{array}$ \\
\hline
\end{tabular}

Fonte: Autores (2018)

No Apêndice 1 apresenta-se um mapa de processos com a sequência de etapas e os recursos envolvidos na execução dos macroprocessos de Extração (baseada em COELHO et al., 2016) e Beneficiamento do minério de ferro, desenvolvidos no Pará.

\section{CONSIDERAÇÕES FINAIS}

Dada a importância econômica mundial, nacional (Brasil) e estadual (Pará) do minério de ferro, com base na identificação das operações desenvolvidas por uma mineradora atuante neste estado e na análise de componentes logísticos associados a estas operações, foi possível alcançar o objetivo desta pesquisa, já que foi caracterizada a logística dos macroprocessos de extração e beneficiamento do minério de ferro no Pará. 
No que concerne ao componente Instalações, observou-se, em nível macro, as minas (extração) e a usina (beneficiamento), ambas localizadas próximas ao município de Parauapebas-PA. Porém, mais internamente nestas instalações, ou seja, em nível micro, foram identificados vários pontos de agregação de valor (extração, "pulmões", depósitos (estéril), britadores, pátios de armazenagem/estocagem, silos etc.), instalados ao longo da cadeia produtiva, com vistas a manter o fluxo de minério de ferro (subprodutos e produtos) ordenado e logicamente aderente ao atendimento às demandas previstas.

Em relação aos estoques, observou-se que estes se localizam tanto em pontos fixos (instalações), nas Minas ("pulmões") e Usina (pátios de estocagem/armazenagem e silos), quanto em trânsito (CFE, correias transportadoras e recuperadoras) e a sua baixa variedade e altos volumes definem o uso de estruturas logísticas (instalações e transporte) que possibilitam maior fluidez (fluxos mais contínuos) de materiais (minério de ferro, estéril, granulado, sinter feed e pelet feed) e, consequentemente, maiores possibilidades de ganhos em escala nos dois macroprocessos analisados.

Constatou-se que a infraestrutura de transporte identificada (CFE, correias transportadoras e recuperadoras) é aderente aos volumes e valores agregados aos materiais movimentados, permitindo que as atividades sejam conectadas adequadamente.

A informação, como em qualquer sistema logístico, apresentou-se como fundamental ao alcance esperado de desempenho para todos os processos considerados na extração e no beneficiamento, sendo componente essencial para integração e maior efetividade das operações. O monitoramento de todo o processo torna-se mais eficiente quando são utilizadas tecnologias apropriadas, como monitoramento via satélite, que vem permitindo um controle mais preciso das etapas consideradas na mineradora estudada.

Por fim, como propostas de pesquisas futuras, foi possível identificar como oportunidades tanto a ampliação deste estudo de mapeamento e caracterização logística para os demais macroprocessos (Transporte ferroviário e Expedição) que compõem a cadeia produtiva do minério de ferro, desenvolvida pela empresa analisada (1), como o emprego dos mapas de processos gerados como base para concepção e proposição de modelos de simulação computacional (2), capazes de proporcionar maior conhecimento e entendimento sobre o desempenho das operações e comportamento das variáveis logísticas envolvidas nos processos que compõem esta importante cadeia produtiva. 


\title{
Logistics of the Processes in an Iron Ore Mining Company in the State of Para
}

\begin{abstract}
In the current global scenario and the consequent necessity of increasing competitiveness in all economic sectors, the logistics study has been gradually rising its importance within organizations, since it has become recognized as one of the main areas of generating knowledge of advantages competitive. This research aimed to characterize the logistical components of macro processes of Extraction and Beneficiation in an iron mining company located in Pará, describing the support for strategic decisions and aiming to establish efficient operational processes. Moreover, this article configured as a case study, where drivers and resources logistical involved during the macro processes above mentioned were identified and mapped. To achieve the proposed objective, an bibliographic and documentary review about the processes study was performed, providing more detail about the logistic associated to iron ore production chain in state of Pará. As well as how the logistics resources involved in the steps considered. Therefore, a summary table identified the resources and a process map shown how these resources were consumed in the processes studied, besides showing the consequences of the use of these resources in the production chain analyzed.
\end{abstract}

KEYWORDS: Iron ore supply chain; Process mapping; Operational logistics drivers. 


\section{REFERÊNCIAS}

ARAUJO, L. C. G.; GARCIA, A. A.; MARTINES, S. Gestão de processos: melhores resultados e excelência organizacional. São Paulo: Atlas, 2011.

BALLOU, R. H. Logística empresarial: transporte, administração de materiais e distribuição física. 5ạ ed. Porto Alegre: Bookman. 2006.

BALLOU, R. H. Gerenciamento da cadeia de suprimentos: planejamento, organização e logística empresarial. 4a ed. Porto Alegre: Bookman, 2001.

BOWERSOX, D. J.; CLOSS, D.J.; COOPER, M. B.; BOWERSOX, J. C. Gestão Logística da Cadeia de Suprimentos. Porto Alegre: AMGH, 2014

BRANCO, N. C. N. M. Planejamento Operacional de Lavra de Minério de Ferro no Estado do Pará: Proposta de Simulação-Otimização de Recursos Logísticos na Etapa Mina. 2013. 121 f. Dissertação (Pós-graduação) - Curso de Engenharia Industrial, PUC-Rio, Rio de Janeiro, 2013.

CABRAL, F. Vale inova para manter mineração do Brasil em posição de destaque no mercado internacional. Disponível em: http://revistanossaeconomia.com.br/2016/05/11/vale-inova-para-mantermineracao-do-brasil-em-posicao-de-destaque-no-mercado-internacional/. Acesso: 28 de nov. 2016.

CANDIDO, R. M.; SILVA, M. T. F. M.; ZUHLKE, R. F. Implantação de gestão por processos: Estudo de caso numa gerência de um centro de pesquisas. In: Encontro Nacional de Engenharia de Produção, 27, 2008. Anais ..., Rio de Janeiro: RJ, 2008.

CARNEIRO, C. M. B.; ZORZAL, E. J.; SANTO; G. P.; BASTOS, M. M. M.; NUNES, R. V; NUNES, R. V. A redução dos custos no uso de arranjos produtivos locais na gestão competitiva da logística de suprimentos. Estudo de caso no APLT Leite \& Sol da cadeia produtiva do leire no estado do Ceará. Revista Produção Online, Florianópolis, Edição especial, 2007. Disponível em: https://producaoonline.org.br/rpo/article/viewFile/60/60 . crossref

CARVALHO, P. S. L.; SILVA, M. M.; ROCIO, M. A. R.; MOSZKOWICZ, J. Minério de ferro. BNDES Setorial, Rio de Janeiro, n. 39, 2014. Disponível em: https://web.bndes.gov.br/bib/ispui/handle/1408/4802. Acesso em: 19 set. 2016. 
CHOPRA, S. MEINDL, P. Gerenciamento da Cadeia de Suprimentos: Estratégia, planejamento e operação. $1^{\circ}$ ed., São Paulo: Pearson Education do Brasil, 2003.

CHOPRA, S.; MEINDL, P. Gestão da Cadeia de Suprimentos: Estratégia, planejamento e operações. São Paulo: Pearson, 2016.

CHRISTOPHER, M. Logistic and supply chain management. 5 ed. Reino Unido: FT Publishing, 2016.

COELHO, F. C.; MONTEIRO, N. J.; MELO, A. C. S.; NUNES, D. R. L.; MARTINS, V. W. B. Modelo de simulação da atividade de lavra em minas a céu aberto: um estudo de caso em uma mineradora no Estado do Pará. InterScience Place, n. 1, v. 11, p. 122 - 139. Disponível em:

http://www.interscienceplace.org/isp/index.php/isp/article/view/477. Acesso: 28 de nov. 2016. crossref

CORRÊA, H. L. Gestão de Redes de Suprimento: Integrando Cadeias de Suprimento no Mundo Globalizado. São Paulo: Editora Atlas, 2010.

CSCMP. Council of Supply Chain Management Professionals. Logística. Disponível em http://cscmp.org/aboutcscmp/Definitions.asp. Acesso em: 09 set. 2016.

D’ASCENÇÃO, L. C. M. Organização, Sistemas e Métodos: Análise, Redesenho e Informatização de Processos. São Paulo: Atlas, 2001.

DIAS, M.A. Logística, transporte e infraestrutura: a armazenagem, operador logístico, gestão TI, multimodal. São Paulo: Editora Atlas, 2012.

DNPM - DEPARTAMENTO NACIONAL DE PRODUÇÃO MINERAL. Anuário Mineral Brasileiro - 2014. 34a ed. Dez. 2014, 152p. Disponível em: http://www.dnpm.gov.br/dnpm/sumarios/sumario-mineral-2014. Acesso em: 19 set. 2016.

FARIA, P. H. L.; RIBEIRO, J. L. D.; VIANA, H. R. G. Modelo de simulação para captura e aproveitamento de ociosidade para manutenção em sistemas de expedição de minérios. Revista Produção Online, Florianópolis, v. 16, n. 4, p. 1142-1171, 2016. Disponível em: https://producaoonline.org.br/rpo/article/view/1990/1465. Acesso em: 19 set. 2016. crossref 
FLEURY, P. F. Supply Chain Management: Conceitos, Oportunidades e Desafios da Implementação. 2006. Disponível em:

http://professorricardo.tripod.com/Artigo 15.pdf . Acesso em: 30 jan. 2017.

FLEURY, P. F.; WANKE, P.; FIGUEIREDO, K. F. Logística empresarial: a perspectiva brasileira. São Paulo: ED. Atlas, 2000.

FLEURY, P. F.; WANKE, P.; FIGUEIREDO, K. F. (Org). Logística e gerenciamento da cadeia de suprimentos: Planejamento do fluxo de produtos e dos recursos. 7. Reimpr. São Paulo: Atlas S.A, 2012, Cap. 2, 49p.

FONTES, A.; FONTES, F. Estrutura e Processos Organizacionais. Rio de Janeiro: Fundação CECIERJ, 2008

GODOY, L. P.; NETO, A. C.; LORENZETT, D. B.; GUARIENTI, E. P. Melhoria contínua dos processos e combate ao desperdício através da ferramenta QFD: O caso da metalúrgica. Revista Produção Online, Florianópolis, v. 13, n. 2, p. 417-449, 2013. Disponível em: https://www.producaoonline.org.br/rpo/article/view/974 . Acesso em: 15 mar. 2017. crossref

GONÇALVES, A. T. P.; ALMEIDA JUNIOR, J. Mapeamento de processos como ferramenta de identificação de fatores de impacto nas paradas não programadas do processo produtivo: estudo de caso em uma fábrica de cerâmica vermelha no estado da Paraíba. In: Simpósio Internacional de Gestão de Projetos, 1, 2012, São Paulo. Anais SINGEP, São Paulo: S.I, 2012.

GONÇALVES, A. T. P; LEITE, M. S. A; SILVA, R. M. Um estudo preliminar sobre as definições e as diferenças dos principais tipos de arranjos empresariais. Revista Produção Online, Florianópolis, v.12, n. 3, p. 827-854, jul./set. 2012. crossref

GONÇALVES, T. B. L., FEIJO, J. L., SANTOS JUNIOR, E. C., ROCHA, C. I. L. Análise da cadeia produtiva do açaí: uma abordagem voltada ao estudo dos componentes de desempenho logístico. In: Encontro Nacional de Engenharia de Produção, 32., 2012, Bento Gonçalves. Anais... Bento Gonçalves: ENEGEP, 2012.

HAMMER, M.; CHAMPY, J. Reengenharia: Revolucionando a Empresa em Função dos Clientes, da Concorrência e das Grandes Mudanças da Gerência. 4ạ Ed. Rio de Janeiro: Campus, 1994.

IBRAM - INSTITUTO BRASILEIRO DE MINERAÇÃO. Informações e análises da economia mineral brasileira. 9a ed. Set. 2015. 25p. Disponível em:www.ibram.org.br/sites/1300/1382/00002806.pdf. Acesso em: 19 set. 2016. 
LEITE, G. M.; BEILER, B.; FERREIRA, C.; KORS,T.; IGNÁCIO, P. S. A. Proposta de u modelo conceitual para tomada de decisão entre centralizar ou descentralizar armazéns. Revista Produção Online, Florianópolis, v. 16, n. 4, p. 1262-1284, 2016. Disponível em:

https://www.producaoonline.org.br/rpo/article/viewFile/2287/1474. Acesso em: 5 fev. 2017. crossref

LOVÓN-CANCHUMANI, G. A.; LIMA, F. M. R. S.; OLIVEIRA, P. P. Avaliação do ciclo de vida na mineração: estudos da produção de minério de ferro. Rio de Janeiro: CETEM/MCTI, 2015. Disponível em: http://biblio.cetem.gov.br/handle/cetem/1923. Acesso em: 3 jan. 2017. crossref

MILAN, G. S.; VERSETTI, R. Melhorias em processos com impacto na eficiência operacional: um estudo ambientado em um laboratório de análises clínicas. Revista Produção Online, Florianópolis, v. 16, n. 4, p 1031-1056, 2012. Disponível em: https://producaoonline.org.br/rpo/article/view/1004/964. Acesso em: 14 jan. 2017. crossref

NAGEL, C.; ROSEMANN, M. Process engineering. Curso de pós-graduação à distância. Queensland (AU): Queensland University of Technology, 1999.

OLIVEIRA, I. S.; BELTRÃO, A. M. C.; MELO, A.C.S.; SILVA, R. W.; GALIZA, M. S. Análise de motivos de devoluções de mercadorias em um centro de distribuição na cidade de Ananindeua: Uma abordagem a luz dos componentes logísticos. In: Encontro Interestadual de Engenharia de Produção. João da Barra: Einepro, 2015.

SANTOS, R. F; MARINS, F. A. S. Integrated model for reverse logistic mangement of electronic produts and components. Procedia Computer Science 55, pp. $575-$ 585, 2015. Disponível em:

http://www.sciencedirect.com/science/article/pii/S1877050915015227. Acesso em: 20 set. 2016. crossref

SIMCHI-LEVI, D. Cadeia de suprimentos: projeto e gestão. Porto Alegre: Bookman, 2010.

SLACK, N.; CHAMBERS, S.; JOHNSTON, R. Administração da Produção. 3 a Ed. São Paulo: Atlas, 2009.

TAN, K. C. Supply Chain Management: Practices, Concerns and Performance Issues. Journal of Supply Chain Management 38 (4), pp. 42 - 53, December 2002. Disponível em: http://onlinelibrary.wiley.com/doi/10.1111/j.1745-

493X.2002.tb00119.x/epdf?r3 referer=wol\&tracking action=preview click\&sho 
$\underline{w}$ checkout $=1 \&$ purchase referrer=onlinelibrary.wiley.com\&purchase site licens e=LICENSE DENIED. Acesso em: 20 set. 2016. crossref

USGS. United States Government Printing Office. Mineral Commodity

Summaries. Washington, 201p, 2013. Disponível em:

http://minerals.usgs.gov/minerals/pubs/mcs/2013/mcs2013.pdf. Acesso em: 19 set. 2016.

VALE, Relatório de Produção VALE 2016. Disponível em:

http://www.vale.com/PT/investors/information-market/quarterly-

results/ResultadosTrimestrais/2016\%204Q\%20Production\%20Report p.pdf.

Acesso: 16 mar. 2017

VALE. Infográfico Vale. Disponível em:

http://www.vale.com/brasil/PT/business/mining/iron-ore-

pellets/Documents/carajas/index.html. Acesso em: 20 set. 2016.

VERHETSEL, A; KESSELS, R.; PETER, G.; ZIJLSTRA T.; BLOMME N.; CANT, J. Location of logistics companies: a stated preference study to disentangle the impact of accessibility. Journal of Geography 42, pp. 110 - 121, 2015. Disponível em: http://www.sciencedirect.com/science/article/pii/S0966692314002464. Acesso em: 20 set. 2016. crossref

Recebido: 16 Out. 2018

Aprovado: 28 Jan. 2020

DOI: $10.3895 /$ gi.v15n4.8947

Como citar:

SALOMÃO, B.H.N. et al. Logística dos macroprocessos em uma processadora de minério de ferro atuante no estado do Pará. R. Gest. Industr., Ponta Grossa, v. 15, n. 4, p. 121-139, Out./Dez. 2019. Disponível em: http://periodicos.utfpr.edu.br/revistagi. Acesso em: 2019.

Correspondência:

Bárbara Heliodora Negreiros Salomão

Universidade do Estado do Pará - UEPA, Brasil.

Direito autoral: Este artigo está licenciado sob os termos da Licença Creative Commons-Atribuição 4.0

Internacional.

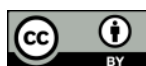



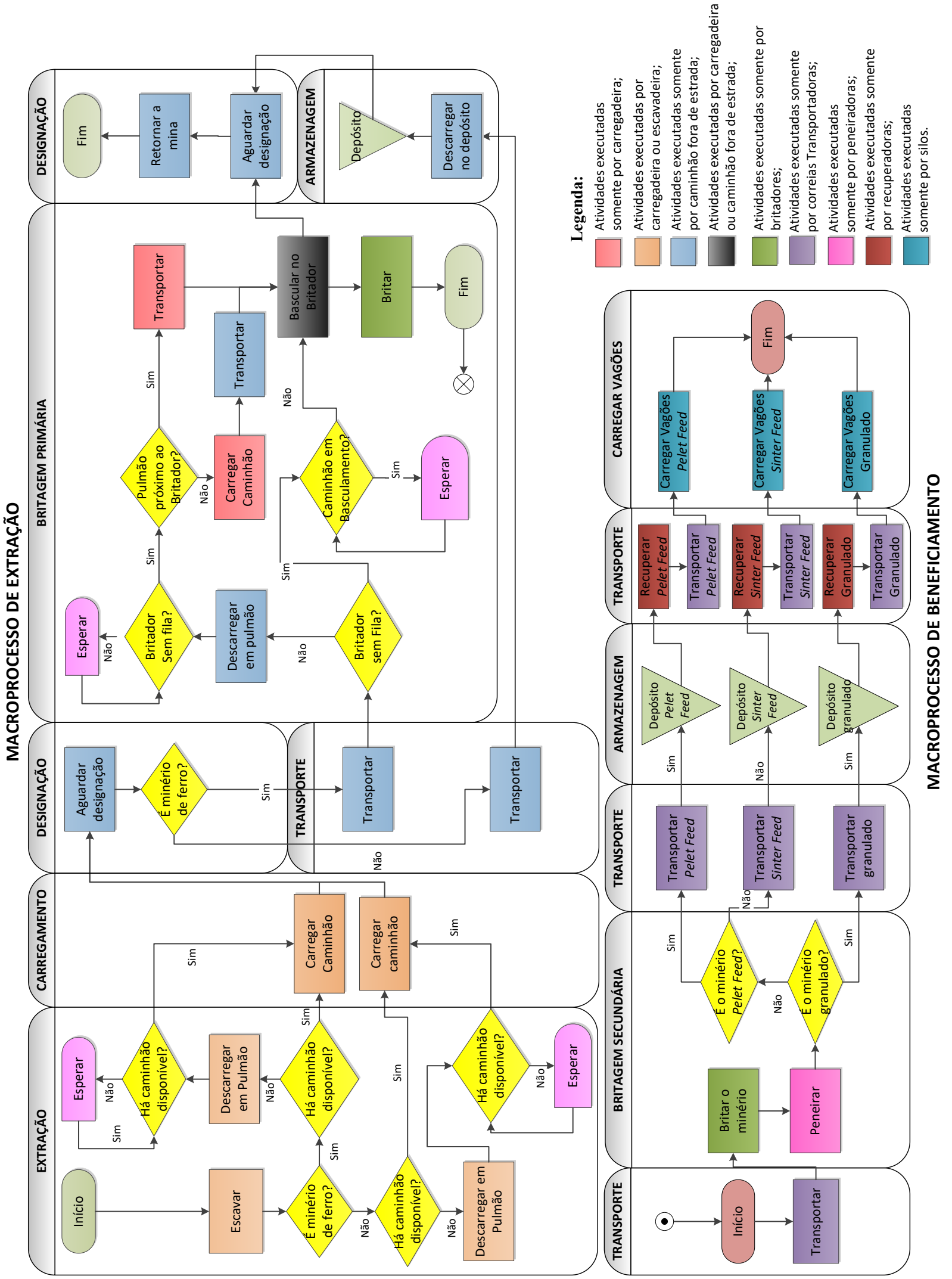